http://jmscr.igmpublication.org/home/

ISSN (e)-2347-176x ISSN (p) 2455-0450

crossref DOI: https://dx.doi.org/10.18535/jmscr/v8i11.67

Journal Of Medical Science And Clinical Research

\title{
Ectopic Acth Secreting Tumor Causing Rapidly Progressive Cushing's Syndrome
}

Authors

\section{Dr Aditya Sanjeevi ${ }^{*}$, Dr M. Rajkumar ${ }^{2}$, Dr P. Sathyamurthy ${ }^{3}$, Dr Bhargavi. $\mathbf{R}^{4}$}

${ }^{1}$ Final year resident in the Department of General Medicine, Sri Ramachandra Institute of Higher Education and Research, Chennai

${ }^{2}$ Head of Department and Professor of General Medicine, Sri Ramachandra Institute of Higher Education and Research, Chennai

${ }^{3}$ Professor in the Department of General Medicine, Sri Ramachandra Institute of Higher Education and Research, Chennai

${ }^{4}$ Assistant Professor in the Department of General Medicine, Sri Ramachandra Institute of Higher Education and Research, Chennai

*Corresponding Author

Dr Aditya Sanjeevi

\begin{abstract}
Summary
Patient's clinical presentation was remarkable for recent onset abdominal distension, pedal edema and facial puffiness. Has been consuming alcohol for the past 15 years.

History was unremarkable for weight loss or chronic cough. Hewas found to have hyperglycemia and hypertension a week before presentation and started on T. Metformin and Enalapril.

Physical exam revealed a distended abdomen with shifting dullness and there was generalised hyperpigmentation. CECT Abdomen was proceeded with since the USG Abdomen showed multiple lesions in the Liver and it showed Chronic parenchymal liver disease with a few arterial phase enhancing lesion scattered in both lobes of liver-suggestive of metastasis / multifocal hepatocellular carcinoma. Serum alfafetoprotein was normal (5.20). The patient meanwhile also had refractory hypokalemia despite multiple corrections with intravenous Potassium Chloride and Metabolic alkalosis.

Hence in the setting of possible metastatic malignancy with hypertension, hyperglycemia, refractory hypokalemia and metabolic alkalosis a serum 8 am Cortisol was sent which came out to be $117.2 \mathrm{ug} / \mathrm{dl}$, this was repeated - $130 \mathrm{ug} / \mathrm{dl}$. A serum ACTH level was sent which was $>1250 \mathrm{pg} / \mathrm{ml}$. Hence a diagnosis of ECTOPIC ACTH induced Cushing's was made and the patient underwent a DOTA SCAN to find the primary and it revealed a Somatostatin receptor expressing primary tumor in left lung upper lobe with ipsilateral hilar, mediastinal lymph nodal and liver spread with extensive skeletal metastasis. The grave prognosis was explained to the patient's care takers and they were not willing for further management. Subsequently, through telephonic conversation it was learnt that the patient passed away a few days after being discharged.
\end{abstract}

\section{Background}

Cushing's syndrome (CS) is caused by excess glucocorticoid levels and may be due to corticosteroid treatment, pituitary tumour (Cushing's disease $(\mathrm{CD})^{[1]}$, cortisol-secreting adrenal tumour or increased production of 
adrenocorticotropic hormone (ACTH) by an extrapituitary (ectopic) tumour ${ }^{[2]}$. Ectopic ACTH secretion (EAS) is a very rare cause of Cushing's syndrome accounting for about $15 \%$ of cases, and about $20 \%$ of ACTH-dependent cases. Virtually all tumors have been associated with EAS, however lung cancer (including small cell carcinoma and bronchial carcinoids) accounts for half of the cases and more than a quarter of the cases remains occult without determining the source of the ectopic secretion ${ }^{[3]}$. The type of tumor strongly influences the clinical course: Ectopic ACTH Secretion by small cell carcinoma of Lung and other malignant neoplasms typically leads to early appearance and more pronounced metabolic alterations ${ }^{[4]}$. In contrast, less aggressive tumors with a delayed diagnosis show clinical characteristics similar to those of pituitary Cushing's syndrome with Cushingoid symptoms e.g. Bronchial carcinoids ${ }^{[4]}$.

\section{Case Presentation}

65 year old male was admitted with complaints of abdominal distension, bilateral lower limb swelling and facial puffiness for the past 20 days, loss of appetite past 10 days and irrelevant talk past 5 days.

Recently diagnosed Hypertension and Diabetes mellitus on treatment with T. Enalapril and T. Metformin.

He was a 10 pack year smoker for 45 years and an occasional drinker.

Physical examination was remarkable for a distended abdomen with shifting dullness and generalised hyperpigmentation. BP-150/80mmhg and $\mathrm{PR}-92 / \mathrm{min}$ respiratory rate of 14 per minute, and temperature of 98.4 degree Farhenheit.

Initially the patient was thought to have Decompensated Chronic Liver Disease with Grade 2 Hepatic Encephalopathy.

CECT Abdomen was proceeded with since the USG Abdomen showed multiple lesions in the Liver and it showed Chronic parenchymal liver disease with a few arterial phase enhancing lesion scattered in both lobes of liver - suggestive of metastasis / multifocal hepatocellular carcinoma.

However, the Serum alfafetoprotein was normal (5.20).

The patient meanwhile also had refractory hypokalemia despite multiple corrections with intravenous Potassium Chloride and Metabolic alkalosis.

Blood biochemistry results were as follows: hypokalemia of $2.1 \mathrm{mEq} / \mathrm{L}$ with severe metabolic alkalosis (pH 7.51, HCO3 38.7, pO2 50, Sat O2 90\%).

Hence in the setting of possible metastatic malignancy with recent onset hypertension and hyperglycemia, refractory hypokalemia and metabolic alkalosis, Ectopic ACTH secretion was suspected and a serum 6 am Cortisol was sent which came out to be $117.2 \mathrm{ug} / \mathrm{dl}$, this was repeated $-130 \mathrm{ug} / \mathrm{dl}$.

Serum ACTH was > $1250 \mathrm{pg} / \mathrm{ml}$.Hence a diagnosis of ECTOPIC ACTH induced Cushing's was made and the patient underwent a GALLIUM DOTANOC PET-CT SCAN to find the primary and it revealed a Somatostatin receptor expressing primary tumor in left lung upper lobe with ipsilateral hilar, mediastinal lymph nodal and liver spread with extensive skeletal metastasis.

Because of the patient's rapid deterioration no more diagnostic studies were performed.

The grave prognosis was explained to the patient and the attenders and they were not willing for further management and hence was discharged.

Through telephonic conversation later it was known that unfortunately the patient had passed away 5 days after discharge.

An autopsy was not performed. 


\section{JMSCR Vol||08||Issue||11||Page 393-397||November}

Investigations

\begin{tabular}{|l|l|l|l|}
\hline PARAMETER & \#1 & \#2 & \#3 \\
\hline POTASSIUM & 2.1 & 2.5 & 37 \\
\hline BICARBONATE & 37 & 36 & \\
\hline MAGNESIUM & 2.1 & 130 & \\
\hline $\begin{array}{l}\text { SERUM 6 AM } \\
\text { CORTISOL }\end{array}$ & 117.2 & & \\
\hline SERUM ACTH & $>1250$ & 232 & \\
\hline SGOT & 107 & 302 & \\
\hline SGPT & 122 & 325 & \\
\hline ALP & 155 & 2.5 & \\
\hline ALBUMIN & 2.8 & 2.1 & \\
\hline GLOBULIN & 2.3 & & \\
\hline ALPHA FETOPROTEIN & 5.20 & 2.5 & \\
\hline SAAG RATIO & & & \\
\hline
\end{tabular}

\section{Differential Diagnosis}

The patient's presentation was with abdominal distension and lower limb swelling. Hence, a diagnosis of Hepatic failure was considered.

However, the metabolic profile clearly pointed towards ectopic ACTH secretion, the source of which was further elucidated on Gallium DOTA NOC scan.

\section{Treatment}

During the course of hospital stay, correction of metabolic abnormalities with Injection Potassium chloride $40 \mathrm{mEq} / \mathrm{L}$ in $500 \mathrm{ml}$ Normal saline was attempted. However, the patient had refractory hypokalemia despite receiving 4 such corrections over 48 hours. In view of the rapid clinical progression and the grave prognosis of metastatic small cell lung cancer, the patient's care takers wanted conservative management rather than aggressive therapy and the patient was discharged home with antihypertensives, human insulin subcutaneous injection and oral ketoconazole.

\section{Outcome and Follow-Up}

Through telephonic conversation, it was learnt that the patient had passed away 5 days after discharge.

\section{CECT Abdomen- arterial phase enhancing lesions in the Liver}

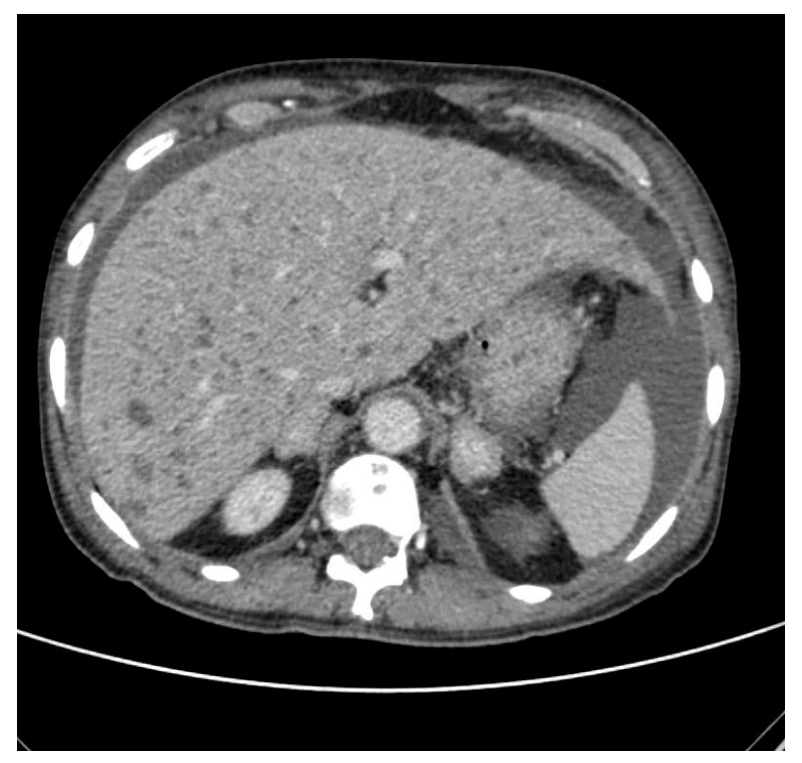




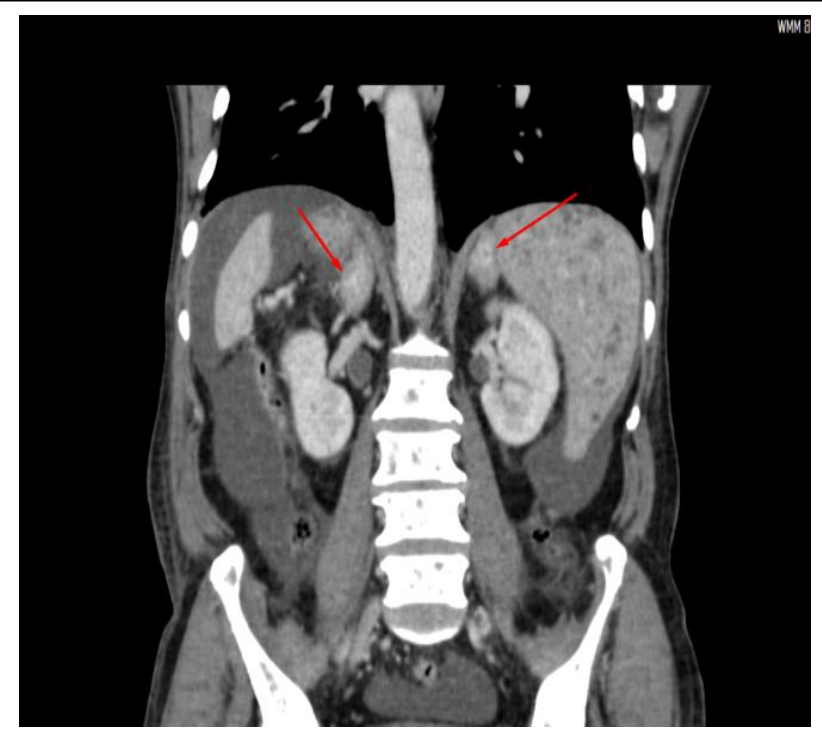

\section{Gallium DOTANOC PET Scan}
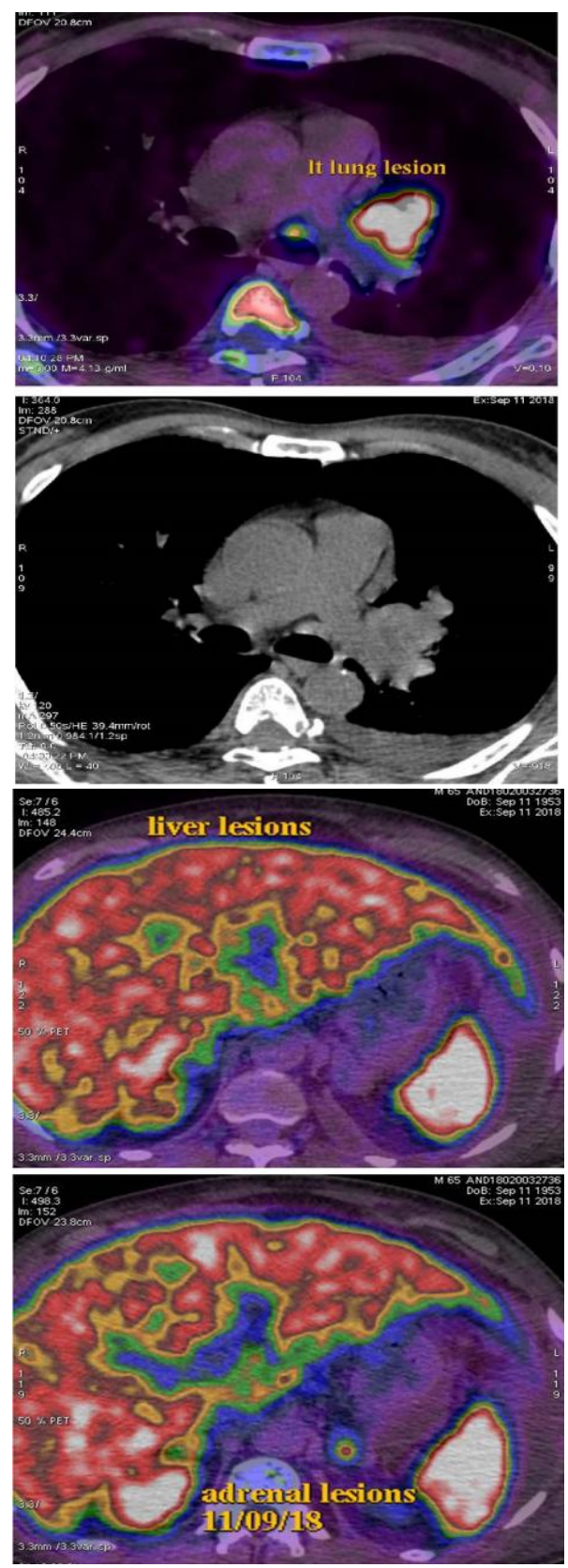

\section{Discussion}

The gold standard for the differential diagnosis of pituitary and ectopic ACTH-dependent Cushing's syndrome is the bilateral inferior petrosal sinus sampling after administration of CRH $(1 \mu \mathrm{g} / \mathrm{kg})$.

A ratio greater than 3.0 after the administration of CRH is consistent with Cushing's disease.

Patients with Ectopic ACTH Syndrome will have a ratio less than 2 before and after $\mathrm{CRH}$ administration because the endogenous hypercortisolism suppresses pituitary ACTH release through negative feedback mechanisms (sensitivity 97\%, specificity 100\%). High-dose dexamethasone suppression tests have lower sensitivity $(81 \%)$ and specificity $(67 \%)^{[8]}$ In this case, the rapid clinical course and financial constraints did not permit pituitary magnetic resonance imaging or the tests generally considered as gold standards for ectopic ACTH dependent Cushing's syndrome. When a patient presents with refractory hypokalemia, metabolic alkalosis, new onset hypertension and hyperglycemia with a rapid deterioration in clinical condition and neuropsychiatric symptoms, Ectopic ACTH Secretion must be considered ${ }^{[5,6]}$. Gallium DOTANOC PET CT Scan aids in the identification of the primary causing the Ectopic ACTH Secretion and the extent of spread. The Small Cell Lung Cancer is a well recognized origin of Ectopic ACTH Secretion and patients with extensive disease have a median survival duration of 6 weeks $^{[7]}$. Ectopic ACTH secretion due to aggressive tumors like Small Cell Lung Carcinoma may present with only Metabolic abnormalities and no Cushingoid features. In patients with ectopic ACTH secretion due to malignancy, excision of the primary tumor is considered to be the preferred modality of treatment ${ }^{[9]}$. Other measures to control features of hypercortisolism include pharmacological and surgical. The surgical measure that offers immediate relief of symptoms is bilateral adrenalectomy which is done nowadays through the laparoscopic route to decrease the morbidity associated with the procedure ${ }^{[10]}$. Drugs used in 
the treatment of ectopic ACTH secretion include steroidogenesis inhibitors such as Metyrapone and Ketoconazole which can be used as monotherapy or in combination ${ }^{[11]}$. Etomidate, a hypnotic agent is also a powerful inhibitor of steroidogenesis. Mifepristone, cabergoline, kinase inhibitors such as sunitinib and somatostatin analogues have also been tried in the treatment of ectopic ACTH secretion to control the features of hypercortisolism.

\section{References}

1. Arnaldi G, Angeli A, Atkinson AB, et al. Diagnosis and complications of Cushing's syndrome: a consensus statement. J Clin Endocrinol Metab 2003;88:5593-602

2. Cushing $\mathrm{H}$. The basophil adenomas of the pituitary body and their clinical manifestations (pituitary basophilism). 1932. Obesity Res 1994;2:486-508

3. Wajchenberg BL, Mendonca BB, Liberman B, Albergaria Pereira MA, Campos Carneiro P, Wakamatsu A, Kirschner MA: Ectopic adrenocorticotropic hormone syndrome. Endocr Rev 1994, 15:752-787.

4. Isidori Andrea M, Andrea Lenzi: Ectopic ACTH syndrome. Arq Bras Endocrinol Metab 2007, 51:1217-1225

5. Isidori Andrea $M$, Kaltsas Gregory $A$, Carlotta Pozza, VanniFrajese, John Newell-Price, Reznek Rodney H, Jenkins Paul J, Monson John P, Grossman Ashley B, Michael Besser G: The ectopic adrenocorticotropin syndrome: clinical features, diagnosis, management, and long-term follow-up. J Clin Endocrinol Metab 2006, 91:371-377.

6. IoannisIlias, Torpy David J, Karel Pacak, Nancy Mullen, Wesley Robert A, Nieman Lynnette K: Cushing's syndrome due to ectopic corticotropin secretion twenty years' experience at the national institutes of health. J Clin Endocrinol Metab 2005, 90:4955-4962.

7. Frumencio Medina M, Margarita Salazar F, Cecilia García S, Francisco Franco M: Epidemiología descriptiva del cáncer pulmonar en el Instituto Nacionale de Enfermedades Respiratorias México 19972000. Rev Inst Nal Enf Resp Mex 2002, 15:149- 152 .

8. Irma Hernandez, Ana Laura Espinoza-delos-Monteros, Victoria Mendoza, Sonia Cheng, Mario Molina, Ernesto Sosa, Mercado Moises: Ectopic ACTH-secreting syndrome: a single center experience report. Arch Med Res 2006, 37:976-980.

9. Aniszewski JP, Young WF, Thompson GB, Grant CS, van Heerden JA. Cushing syndrome due to ectopic adrenocorticotropic hormone secretion. World Journal of Surgery 200125934 940.

10. Zeiger MA, Fraker DL, Pass HI, Nieman LK, Cutler GB, Chrousos GP, Norton JA. Effective reversibility of the signs and symptoms of hypercortisolism by bilateral adrenalectomy. Surgery 1993114 11381143.

11. Daniel E, Aylwin S, Mustafa O, Ball S, Munir A, Boelaert K, Chortis V, Cuthbertson DJ, Daousi C, Rajeev SP et al. Effectiveness of metyrapone in treating Cushing's syndrome: a retrospective multicenter study in 195 patients. Journal of Clinical Endocrinology and Metabolism $20151004146-4154$. 